\title{
Measurement of Dynamic Hyperinflation During the 6-Minute Walk Test Using a Mobile Device
}

\author{
Roy Meys, Mart Schiefer, Selma B de Nijs, Henk Bindels, \\ and Martijn D de Kruif
}

\begin{abstract}
BACKGROUND: Dynamic hyperinflation is a major cause of dyspnea in patients with COPD. Dynamic hyperinflation is usually measured with cardiopulmonary exercise testing, but this test requires maximal effort from the patient, and inspiratory capacity (IC) measurements may influence test results. This study investigated another approach by measuring dynamic hyperinflation during the more natural and better-tolerated 6-min walk test (6MWT), using a mobile system for IC measurements. METHODS: Twenty subjects were studied, including 10 healthy subjects and 10 subjects with COPD. Each subject performed a pair of 6MWTs. RESULTS: The study showed that test-retest reliability in healthy subjects was excellent (intraclass correlation coefficient 0.995 ). In addition, mean resting $\mathrm{IC}$ in healthy subjects $(3.27 \pm 0.77 \mathrm{~L})$ was not affected at the end of the 6MWT, whereas mean resting IC in subjects with COPD $(2.45 \pm 0.90 \mathrm{~L})$ decreased to $1.93 \mathrm{~L} \pm 0.68 \mathrm{~L}$ at the end of the 6MWT $(P=.004)$. The tolerability of the device for subjects with COPD appeared to be only slightly hampered by an increased sense of dyspnea attributed to wearing a mask. CONCLUSIONS: This study provides a proof of principle for mobile IC measurements during the 6MWT, demonstrating good test performance, reasonable tolerability, and a power to differentiate normal from pathologic conditions. Key words: dynamic hyperinflation; COPD; mobile; 6-min walk test; physiology; exercise. [Respir Care 2019;64(2):182-188. (C) 2019 Daedalus Enterprises]
\end{abstract}

\section{Introduction}

Dynamic hyperinflation is a major cause of dyspnea in patients with COPD. ${ }^{1-4}$ Especially in moderate to severe COPD, dynamic hyperinflation negatively influences exercise tolerance and quality of life. ${ }^{5}$ Dynamic hyperinflation may be measured by determining inspiratory capacity (IC) using either a static technique like metronome-paced tachypnea ${ }^{6}$ or a more natural, dynamic method such as

Drs Schiefer and de Kruif, as well as Mr Meys and Mr Bindels, are affiliated with the Department of Pulmonary Medicine, Zuyderland Medical Center, Heerlen, The Netherlands. Dr de Nijs is affiliated with the Department of Pulmonary Medicine, University Medical Center Utrecht, Heidelberglaan, Utrecht, The Netherlands.

The authors have disclosed no conflicts of interest.

Correspondence: Martijn D de Kruif, Department of Pulmonary Medicine, Zuyderland Medical Center, Henri Dunantstraat 5, 6419 PC, Heerlen, The Netherlands. E-mail: m.dekruif@zuyderland.nl

DOI: $10.4187 /$ respcare.06307 cardiopulmonary exercise testing (CPET) ${ }^{7}$ CPET provides extensive information, but the method is time-consuming and exhausting for the patient, and the IC measurements themselves can influence exercise tolerance. ${ }^{8}$

The 6-min walk-test (6MWT) is a dynamic, submaximal exercise test that is easier to perform than CPET. Moreover, the 6MWT is generally considered to better reflect the functional exercise capability of patients with COPD in everyday life. ${ }^{9}$ In addition, due to the submaximal efforts during the 6MWT, the test results may be less influenced by IC maneuvers. Despite these advantages of the 6MWT, no methods have been validated to date for the measurement of dynamic hyperinflation during this test.

A mobile spirometer can be carried during exertion to enable real-time spirometry during exercise. ${ }^{10}$ One such system, the Oxycon mobile device (CareFusion, San Diego, California), was originally designed as a mobile CPET system focusing on measurements of oxygen consumption and ventilation. However, it was demonstrated that the system also showed promise for studying dynamic hyperinflation during steady-state exercise in healthy subjects ${ }^{11}$ and during the 6MWT in a cohort of male Asian subjects 
with COPD. ${ }^{12}$ Because these studies lacked evaluating 6MWT in healthy subjects and a comparison between subjects with COPD and healthy subjects, concerns remained about the additional clinical value and tolerability of the device, as well as about the potential to differentiate normal conditions from pathologic conditions.

To address these issues, this study aimed to determine test-retest reliability of the Oxycon mobile device for IC measurements during the 6MWT in healthy subjects. Second, we determined the ability of the device to detect dynamic hyperinflation in subjects with COPD and compared the results with those obtained with healthy subjects. Third, we explored the subjective tolerability of the system in subjects with COPD.

\section{Methods}

The study was designed as a prospective cohort study. The study was designed in 2 phases. First, we determined the test-retest reliability of IC measurements using the Oxycon mobile device during the 6MWT with healthy subjects. The Oxycon device is a telemetric breath-by-breath system that consists of a face mask with turbine and integrated $\mathrm{O}_{2}$ and $\mathrm{CO}_{2}$ sensors, a pulse oximeter, and a transmitter unit with a total weight of $900 \mathrm{~g}$ attached to the patient; the receiver unit is connected to a personal computer. ${ }^{10}$ Then we studied the tolerability and diagnostic performance of the Oxycon mobile device during the 6MWT with subjects with COPD, who received a 6MWT as part of regular care in Zuyderland Medical Center, Heerlen, The Netherlands. Permission to perform this study was granted by the medical ethical board of Zuyderland Medical Center.

A group of healthy subjects was recruited among hospital staff. Inclusion criteria for healthy subjects were adult age ( $\geq 18 \mathrm{y}$ ), normal pulmonary function (normal $\mathrm{FEV}_{1}, \mathrm{FVC}$, and total lung capacity; $\mathrm{FEV}_{1} / \mathrm{FVC}>0.70$ ), negative history for pulmonary diseases, no use of asthma or COPD medication, and functionally able to perform a 6MWT. Exclusion criteria for healthy individuals were significant bronchodilator response (increase in $\mathrm{FEV}_{1}$ of FVC of $\geq 12 \%$ or $\geq 200 \mathrm{~mL}$ after $100 \mu \mathrm{g}$ salbutamol) and clinically important cardiovascular conditions (eg, uncontrolled hypertension, unstable angina pectoris, myocardial infarction within 3 months, congestive heart failure).

A group of patients with COPD who performed a 6MWT as part of routine medical care and matched inclusion and exclusion criteria were asked to participate. Inclusion criteria for COPD subjects were adult age ( $\geq 18 \mathrm{y}$ ), a diagnosis of COPD according to GOLD criteria and confirmed by a pulmonologist, including $\mathrm{FEV}_{1} / \mathrm{FVC}<0.70$ and $\mathrm{FEV}_{1}<100 \%$ predicted, smoking history of at least 10 pack-years, full pulmonary function testing (ie, spirometry, functional residual capacity helium dilution, CO-dif-

\section{QUICK LOOK}

\section{Current Knowledge}

Dynamic hyperinflation is often determined with cardiopulmonary exercise testing, but this method has several limitations. Evidence suggests that measuring dynamic hyperinflation may also be feasible during the more natural and better tolerated 6-min walk test (6MWT).

\section{What This Paper Contributes to Our Knowledge}

This study showed that mobile inspiratory capacity measurements during the 6MWT were reproducible in healthy subjects and demonstrated the ability to differentiate normal from pathologic conditions by comparison with subjects with COPD. The mobile inspiratory capacity measurements were reasonably tolerated except in subjects with very severe disease.

fusion measurement, reversibility) within the last 6 months, and functionally able to perform a 6MWT. Exclusion criteria for patients with COPD were use of long-term oxygen therapy, significant bronchodilator response (eg, increase in $\mathrm{FEV}_{1}$ of $\mathrm{FVC}$ of $\geq 12 \%$ or $\geq 200 \mathrm{~mL}$ after $400 \mu \mathrm{g}$ salbutamol), restrictive pulmonary impairment (ie, total lung capacity $<80 \%$ predicted), any active pulmonary comorbidity (eg, pneumonia or pulmonary embolism), COPD exacerbation or any hospitalization during the last 2 months, and cardiovascular conditions (eg, uncontrolled hypertension, unstable angina pectoris, myocardial infarction within 3 months, congestive heart failure).

Pulmonary function testing was performed by the Carefusion MasterScreen PFT system, according to American Thoracic Society/European Respiratory Society guidelines. ${ }^{13}$ The 6MWT was performed using the Vyntus Walk System (Carefusion) and a wireless WristOx2 3150 pulse oximeter (Nonin, Plymouth, Minnesota), according to American Thoracic Society/European Respiratory Society guidelines, with the exception that we used a 21.5 -m corridor circuit instead of 30-m corridor as preferred by the guidelines. ${ }^{9}, 10$ The modified Medical Research Council dyspnea score was noted, as well as Borg scores for dyspnea and lower extremity fatigue before and after the test.

IC measurements were performed in all intervention groups directly prior to, at $2 \mathrm{~min}$, at $4 \mathrm{~min}$, and at completion of a 6MWT using the Oxycon mobile device. Both healthy subjects and subjects with COPD carrying the Oxycon mobile used the same protocol. They performed resting IC measurement 5 times; the reported IC represents the mean IC derived from the best 3 measurements within a 5\% margin. Resting IC measurements were performed while standing upright. Walking IC measurements after 2 min and 4 min were single measurements performed 
while the subject continued walking. Directly after the 6MWT, a final IC measurement was performed.

In the group of healthy subjects, a 6MWT was performed twice while using the Oxycon mobile device to evaluate the test-retest reliability. In the group of subjects with COPD, a 6MWT was performed once while using the Oxycon mobile device, and once without using the device to produce a routine test result for standard medical care.

After completing the 6MWT, subjects with COPD were offered a novel, in-house developed, 10-point questionnaire about the tolerability of the device. Using a weighting of -2 points for complete disagreement, -1 point for disagreement, 0 points for a neutral answer, +1 point for agreement, and +2 points for complete agreement, a negative mean agreement score indicated disagreement and a positive score indicated agreement. A statistical analysis was performed using SPSS Statistics, Version 20.0 (IBM, Armonk, New York); $P<.05$ was considered statistically significant. Intraclass correlation and a Bland-Altman plot were used to evaluate test-retest reliability. $\Delta \mathrm{IC}$ values were classified as positive or negative for dynamic hyperinflation using various cut-off levels for a positive test of $<0 \mathrm{~mL}$, $400 \mathrm{~mL}$, and $<90 \%$ of resting IC. After testing for normality using the Shapiro-Wilks and the Kolmogorov-Smirnov tests, paired $t$ tests were used to compare $6 \mathrm{MWT}$ results.

\section{Results}

\section{Subject Characteristics}

Twenty subjects were studied, including 10 healthy subjects and 10 subjects with COPD. Demographic characteristics and pulmonary function variables of these subjects are shown in Table 1. In healthy subjects, mean $\mathrm{FEV}_{1}$ and $\mathrm{FEV}_{1} /$ FVC were $104 \pm 8 \%$ predicted and $0.76 \pm 0.3$, respectively, and in subjects with COPD these values were $47 \pm 19 \%$ predicted and $0.41 \pm 0.15$, respectively. Mean functional residual capacity was $98 \pm 16 \%$ predicted in healthy subjects and $141 \pm 27 \%$ predicted in COPD subjects.

\section{Test-Retest Reliability}

In healthy subjects, mean IC was $3.27 \pm 0.77 \mathrm{~L}$ at rest (Table 2). This value was not affected at the end of the 6MWT $(3.35 \pm 0.79 \mathrm{~L}, P=.50)$. The $\Delta \mathrm{IC}$ values for the first and second 6MWT were $0.08 \mathrm{~L}(P=.26)$ and $0.02 \mathrm{~L}$ $(P=.67)$, respectively. The intraclass correlation coefficient (ICC) was $0.995,0.993$, and 0.993 for resting IC, IC after $2 \mathrm{~min}$, and IC after $4 \mathrm{~min}$, respectively. At $6 \mathrm{~min}$, ICC was 0.995 .
Table 1. Subject Characteristics

\begin{tabular}{|c|c|c|}
\hline Variable & Healthy Subjects & $\begin{array}{l}\text { Subjects With } \\
\text { COPD }\end{array}$ \\
\hline Gender, $n(\mathrm{M} / \mathrm{F})$ & $3 / 7$ & $7 / 3$ \\
\hline Age, y & $39 \pm 8$ & $64 \pm 11$ \\
\hline Body mass index, $\mathrm{kg} / \mathrm{m}^{2}$ & $24.9 \pm 2.6$ & $25.0 \pm 5.5$ \\
\hline \multicolumn{3}{|l|}{ Before $6 \mathrm{MWT}$} \\
\hline $\mathrm{FEV}_{1}, \mathrm{~L}$ & $3.52 \pm 0.73$ & $1.38 \pm 0.69$ \\
\hline $\mathrm{FEV}_{1}, \%$ predicted & $103 \pm 8$ & $46 \pm 20$ \\
\hline \multicolumn{3}{|l|}{ Post 6MWT } \\
\hline $\mathrm{FEV}_{1}, \mathrm{~L}$ & $3.56 \pm 0.72$ & $1.40 \pm 0.67$ \\
\hline $\mathrm{FEV}_{1}, \%$ predicted & $104 \pm 8$ & $47 \pm 19$ \\
\hline $\mathrm{FEV}_{1} / \mathrm{FVC}, \%$ & $0.76 \pm 0.03$ & $0.41 \pm 0.15$ \\
\hline TLC, $\%$ predicted & $105 \pm 8$ & $115 \pm 13$ \\
\hline FRC, $\%$ predicted & $98 \pm 16$ & $141 \pm 27$ \\
\hline RV/TLC, $\%$ predicted & $82 \pm 11$ & $133 \pm 30$ \\
\hline $\mathrm{D}_{\mathrm{LCO}}, \%$ predicted & $89 \pm 8$ & $52 \pm 20$ \\
\hline $\mathrm{K}_{\mathrm{CO}}, \%$ predicted & $93 \pm 11$ & $60 \pm 20$ \\
\hline \multicolumn{3}{|c|}{$\begin{array}{l}\text { Healthy subjects: } n=10 \text {; subjects with COPD: } n=10 . \text { Values are presented as mean } \pm \text { SD. } \\
6 \text { MWT }=6 \text {-min walk test } \\
\text { TLC }=\text { total lung capacity } \\
\text { FRC = functional residual capacity } \\
\mathrm{RV}=\text { residual volume } \\
\mathrm{D}_{\mathrm{LCO}}=\text { diffusing capacity of the lung for carbon monoxide } \\
\mathrm{K}_{\mathrm{CO}}=\text { carbon monoxide transfer coefficient }\end{array}$} \\
\hline
\end{tabular}

\section{Dynamic Hyperinflation}

The distance walked, heart rate, oxygen saturation, and Borg scores showed no significant differences in subjects with COPD walking with or without the device (Table 2). In contrast, while walking with the device, the mean IC was $2.45 \pm 0.90 \mathrm{~L}$ at rest and $1.93 \pm 0.68 \mathrm{~L}$ at the end of the 6MWT $(\Delta \mathrm{IC}=0.52 \mathrm{~L}, P=.004)$. Because there is no general consensus about the cut-off point of $\Delta \mathrm{IC}$ for dynamic hyperinflation, 3 cut-off values were explored: $<0 \mathrm{~mL},<400 \mathrm{~mL}$, and $<90 \%$ of resting IC. As such, using a cut-off of $\Delta \mathrm{IC}<0$ for the definition of dynamic hyperinflation (and the presence of COPD for the definition of proven hyperinflation), sensitivity and specificity were both $90 \%$. Using a cut-off of $\Delta \mathrm{IC}<400 \mathrm{~mL}$ for the definition of dynamic hyperinflation, sensitivity and specificity were $60 \%$ and $100 \%$, respectively. Using a cut-off of $\Delta \mathrm{IC}<90 \%$ of resting IC for the definition of dynamic hyperinflation, sensitivity and specificity were $70 \%$ and $100 \%$, respectively.

Dynamic changes in time are shown in Figure 1. In healthy subjects, no time differences were observed for IC levels, whereas in subjects with COPD the IC levels decreased significantly after $2 \min (P=.02)$ and did not change from $2 \mathrm{~min}$ to $6 \min (3.35 \pm 0.79 \mathrm{~L}, P=.55)$. In addition, both tidal volume $\left(\mathrm{V}_{\mathrm{T}}\right)$ and breathing frequency reached a steady state in healthy subjects after 
Table 2. 6MWT Measurements Using the Oxycon Mobile Device

\begin{tabular}{|c|c|c|c|c|c|c|}
\hline & \multicolumn{3}{|c|}{ Healthy Subjects } & \multicolumn{3}{|c|}{ Subjects With COPD } \\
\hline & At rest & Test 1 with device & Test 2 with device & At rest & Test 1 without device & Test 2 with device \\
\hline 6MWD, m & NA & $622 \pm 36.5$ & $647 \pm 40.0$ & NA & $448 \pm 64.0$ & $440 \pm 70.3$ \\
\hline Heart rate, beats/min & $94.4 \pm 11.76$ & $135 \pm 10.3$ & $144 \pm 9.81$ & $86.6 \pm 9.63$ & $111 \pm 5.85$ & $115 \pm 11.7$ \\
\hline $\mathrm{S}_{\mathrm{pO}_{2}}, \%$ & $97.0 \pm 1.05$ & $95.8 \pm 1.32$ & $94.3 \pm 1.34$ & $93.3 \pm 3.13$ & $87.5 \pm 4.65$ & $87.6 \pm 5.15$ \\
\hline Borg score dyspnea & $0.00 \pm 0.00$ & $1.65 \pm 1.38$ & $1.55 \pm 1.30$ & $0.50 \pm 0.71$ & $4.00 \pm 2.16$ & $4.80 \pm 2.39$ \\
\hline Borg score leg fatigue & $0.20 \pm 0.63$ & $2.10 \pm 1.64$ & $1.85 \pm 1.33$ & $0.60 \pm 1.26$ & $2.50 \pm 2.46$ & $2.30 \pm 2.21$ \\
\hline Inspiratory capacity, L & $3.27 \pm 0.77$ & $3.35 \pm 0.79$ & $3.40 \pm 0.84$ & $2.45 \pm 0.90$ & NA & $1.93 \pm 0.68$ \\
\hline Total volume, $\mathrm{L}$ & $0.67 \pm 0.12$ & $1.63 \pm 0.32$ & $1.54 \pm 0.29$ & $0.79 \pm 0.14$ & NA & $1.26 \pm 0.35$ \\
\hline Frequency, breaths/min & $16.7 \pm 2.91$ & $26.2 \pm 3.49$ & $28.0 \pm 4.78$ & $19.0 \pm 6.45$ & NA & $29.9 \pm 6.94$ \\
\hline$\dot{\mathrm{V}}_{\mathrm{E}}, \mathrm{L} / \mathrm{min}$ & $11.0 \pm 2.50$ & $42.6 \pm 9.27$ & $42.4 \pm 7.59$ & $14.7 \pm 4.50$ & NA & $37.5 \pm 14.6$ \\
\hline \multicolumn{7}{|c|}{$\begin{array}{l}\text { Values are presented as mean } \pm \mathrm{SD} \text {. } \\
6 \mathrm{MWT}=6 \text {-min walk test } \\
6 \mathrm{MWD}=6 \text {-min walk distance } \\
\mathrm{V}_{\mathrm{E}}=\text { minute volume } \\
\mathrm{NA}=\text { not applicable }\end{array}$} \\
\hline
\end{tabular}
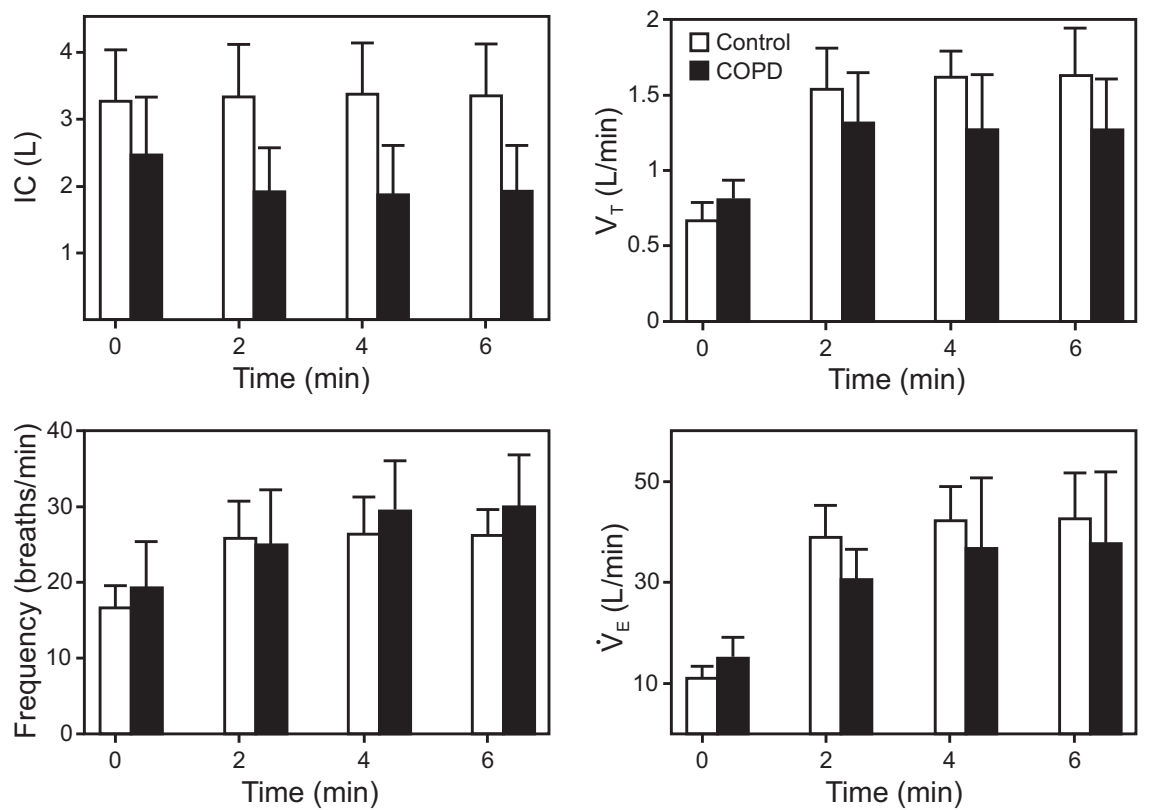

Fig. 1. Dynamic changes over time. $I C=$ inspiratory capacity; $\dot{V}_{E}=$ minute ventilation; $V_{T}=$ tidal volume; White bars $=$ healthy control subjects; Black bars = COPD patients.

2 min $(P<.0001$ for both after 2 min, compared to $P=.21$ for $\mathrm{V}_{\mathrm{T}}$ and $P=.84$ for breathing frequency from $2 \mathrm{~min}$ to $6 \mathrm{~min}$ ). In contrast to healthy subjects, in subjects with COPD breathing frequency showed a trend to only stop increasing until after $4 \mathrm{~min}(P=.74$ and $P=.056$ for healthy subjects and subjects with COPD, respectively, from $2 \mathrm{~min}$ to $4 \mathrm{~min}$ ). After $6 \mathrm{~min}, \mathrm{~V}_{\mathrm{T}}$ was larger in healthy subjects versus subjects with COPD $(P=.02)$, whereas breathing frequency was not significantly different between these groups $(P=.15)$. Overall, total ventilation levels after 6 min did not differ significantly $(P=.37)$.

\section{Test Tolerability}

Subjective evaluation of the 6MWT while using the Oxcyon mobile device by subjects with COPD is shown in Table 3. The evaluation revealed that exercise testing was experienced as being more strenuous while using the device (7 of 10 subjects; mean agreement +0.6 ). The main reason given was increased dyspnea sensation associated with wearing a mask (5 of 10 subjects; mean agreement +0.1$)$. Wearing the backpack containing the device was not perceived as a problem. Two subjects (20\%) indicated that they would not like to repeat the 6WMT with 
Table 3. Tolerability of the Oxycon Mobile Device in Subjects With COPD During the 6MWT

\begin{tabular}{|c|c|c|c|c|c|c|}
\hline & \multicolumn{2}{|c|}{ Disagree } & \multirow{2}{*}{$\frac{\text { Neutral }}{0}$} & \multicolumn{2}{|c|}{ Agree } & \multirow{2}{*}{ Mean Agreement* } \\
\hline & -2 & -1 & & +1 & +2 & \\
\hline The normal 6MWT was physically strenuous. & 2 & 3 & 1 & 4 & 0 & -0.3 \\
\hline The 6MWT with the device was physically strenuous. & 2 & 2 & 1 & 3 & 2 & +0.1 \\
\hline $\begin{array}{l}\text { The 6MWT with the device was more strenuous } \\
\text { than normal 6MWT. }\end{array}$ & 0 & 2 & 1 & 6 & 1 & +0.6 \\
\hline The backpack containing the device limited my test. & 3 & 6 & 1 & 0 & 0 & -1.2 \\
\hline The face mask limited my test. & 0 & 4 & 1 & 5 & 0 & +0.1 \\
\hline $\begin{array}{l}\text { The pulmonary function test before the } 6 \mathrm{MWT} \text { was } \\
\text { physically strenuous. }\end{array}$ & 2 & 7 & 0 & 1 & 0 & -1.0 \\
\hline I experienced more leg fatigue with the device. & 4 & 4 & 1 & 1 & 0 & -1.1 \\
\hline I experienced more dyspnea with the device. & 0 & 4 & 1 & 5 & 0 & +0.1 \\
\hline $\begin{array}{l}\text { I think my walking distance was longer without the } \\
\text { device. }\end{array}$ & 0 & 4 & 1 & 3 & 2 & +0.3 \\
\hline I do not want to perform a future $6 \mathrm{MWT}$ with the device. & 2 & 2 & 4 & 2 & 0 & -0.4 \\
\hline
\end{tabular}

the Oxycon mobile device in the future. Of note, these subjects were characterized by the lowest $\mathrm{FEV}_{1}\left(\mathrm{FEV}_{1}\right.$ $23 \%$ predicted for both subjects). Finally, it should be noted that the researchers observed that the mobile IC measurements were associated with slight pace interruptions during walking. Because this was not anticipated, these pace interruptions were not quantified.

\section{Discussion}

This study demonstrated a high reliability of the Oxycon mobile device for the measurement of dynamic hyperinflation during the 6MWT. In healthy subjects, testretest reliability was 0.995 . The method was further validated in subjects with COPD, where it was shown that dynamic hyperinflation could be detected only in subjects with COPD and not in healthy subjects. The method did not influence the distance walked or other objective parameters. In addition, the test was reasonably well tolerated, despite a generally perceived increased sense of dyspnea that was primarily attributed to the wearing of a mask.

The high test-retest reliability of the Oxycon mobile device for the measurement of IC in healthy subjects is an important prerequisite for validation of the instrument for this purpose. Our data are supported by others in slightly differing settings. In one study, the device was tested in 4 healthy subjects and showed lung function parameters comparable to a stationary system. ${ }^{14}$ In the same small group, an intra-test variability of $11 \%$ was demonstrated when performing a pair of 5-min walking tests. In another group of 10 healthy subjects, it was demonstrated that IC measurements using the Oxycon mobile device in 2 steadystate cycle ergometry tests varied by $<3 \% .^{11}$

Other important issues for a medical test are clinical relevance and minimal impact of the test itself on test results. The clinical relevance of the 6MWT has been extensively validated in COPD and correlates well with desaturation, performance of daily tasks, and sense of dyspnea. ${ }^{15-19}$ The $6 \mathrm{MWT}$ is traditionally used for information about the endurance of the whole-body system, whereas CPET is applied to gather differentiated information about specific organ functioning. ${ }^{20,21}$ The addition of mobile spirometry measurements to the $6 \mathrm{MWT}$ combines the information about whole-body endurance with specific lung organ information, which is clinically valuable information. ${ }^{22}$ The additional information about IC measurements may influence physiotherapeutic approaches as well as drug therapy choices. ${ }^{23-26}$ A number of studies have shown that adding mobile spirometry to the 6MWT did not affect any objectively measured parameters such as distance walked, both in healthy subjects and in patients. ${ }^{10,16,27}$ Also in our study, the system and IC measurements did not affect 6MWT distance. Furthermore, the mean Borg score of the COPD subjects after completing our test using the Oxycon mobile system was comparable to COPD subjects completing a 6MWT without the system, as well as another study with subjects using the system (Borg scores $4.8,5.0$, and 4.6 , respectively). ${ }^{12,28}$

We also explored the subjective tolerability of the test while using the Oxycon mobile device. Despite the relatively small size of the group and a lack of external validation of the questionnaire, the scores provided some useful information. First, subjective dyspnea scores were 
slightly higher using the Oxycon mobile device, which was mainly attributed to wearing a full face mask. Second, the 2 subjects who said they would object to using the Oxycon mobile device again had the most severe air-flow obstruction ( $\mathrm{FEV}_{1}$ for both was $23 \%$ predicted).

Static measurements showed dynamic hyperinflation after finishing the 6MWT before. ${ }^{15,24,29}$ The mobile system that we used also shows that dynamic hyperinflation already occurs in the early phase of the test. After $2 \mathrm{~min}, \mathrm{~V}_{\mathrm{T}}$ reached a plateau phase, whereas breathing frequency continued to increase up to $4 \mathrm{~min}$ in subjects with COPD. These data suggest that after $2 \mathrm{~min}$, neuromechanic dissociation took place, which marks the point where ventilation can only increase by enhancing frequency due to an inability to increase $\mathrm{V}_{\mathrm{T}}{ }^{5}$ Indeed, another investigation showed comparable data and added that Borg scores increased from slight dyspnea to moderate dyspnea after 2 min using the Oxycon device during the 6MWT. ${ }^{12}$ Of interest, the stabilization of ventilation parameters between $4 \mathrm{~min}$ and $6 \mathrm{~min}$ supports the time frame of $6 \mathrm{~min}$ for this test.

The clinically relevant cut-off point for dynamic hyperinflation is still poorly defined.6,30 Difficulties encountered by researchers are poor insights into dyspnea scores and IC measurements during exercise testing, poor static predictors for dynamic hyperinflation, wide variations in patient parameters in COPD, and daily lung function variability in patients with COPD. ${ }^{5,8,25}$ The current method may help provide more information about these factors.

This study has some limitations. The sample size of our study was sufficient to demonstrate primary information about mobile IC measurements during the 6MWT. However, because IC measurements vary significantly in patients with COPD, ${ }^{25}$ the study was not powered to investigate test-retest reliability in subjects with COPD. Another limitation is that the IC measurements in our study were not compared directly to other methods, such as CPET. In addition, the study protocol did not include special training sessions for using the Oxycon mobile device. However, practice was incorporated by measuring resting IC measurements 5 times, and no specific problems were noted. Furthermore, after IC measurement, slight pace interruptions were observed, which were not quantified in frequency, time, or distance; the lack of differences in distance walked suggests that its influence was probably of minor importance. Of note, pace interruption is also noted during IC measurements by CPET. ${ }^{7}$ Finally, larger studies with more sampling time-points with Borg score measurements will be needed to help establish a clinically relevant cut-off value for dynamic hyperinflation, to further define the exact moment of neuromechanic dissociation, and to define the subgroup of patients who are most likely to benefit from the test with the least harm.

\section{Conclusions}

In conclusion, this study provided a proof of principle for mobile IC measurements during the 6MWT. The method showed good test performance, and it was reasonably tolerated; the method also differentiated normal from pathologic conditions. As such, this method shows promise as an alternative technique for measurement of dynamic hyperinflation.

\section{REFERENCES}

1. Garcia-Rio F, Lores V, Mediano O, Rojo B, Hernanz A, LopezCollazo E, et al. Daily physical activity in patients with chronic obstructive pulmonary disease is mainly associated with dynamic hyperinflation. Am J Respir Crit Care Med 2009;180(6):506-512.

2. Pepin V, Saey D, Laviolette L, Maltais F. Exercise capacity in chronic obstructive pulmonary disease: mechanisms of limitation. COPD 2007;4(3):195-204.

3. Palange P, Forte S, Onorati P, Manfredi F, Serra P, Carlone S. Ventilatory and metabolic adaptations to walking and cycling in patients with COPD. J Appl Physiol (1985) 2000;88(5):1715-1720.

4. Hannink JD, van Helvoort HA, Dekhuijzen PN, Heijdra YF. Dynamic hyperinflation during daily activities: does COPD global initiative for chronic obstructive lung disease stage matter? Chest 2010; 137(5):1116-1121.

5. O'Donnell DE. Hyperinflation, dyspnea, and exercise intolerance in chronic obstructive pulmonary disease. Proc Am Thorac Soc 2006; 3(2):180-184.

6. Lahaije AJ, Willems LM, van Hees HW, Dekhuijzen PN, van Helvoort HA, Heijdra YF. Diagnostic accuracy of metronome-paced tachypnea to detect dynamic hyperinflation. Clin Physiol Funct Imaging 2013;33(1):62-69.

7. Ross RM. ATS/ACCP statement on cardiopulmonary exercise testing. Am J Respir Crit Care Med 2003;167(10):1451.

8. Guenette JA, Chin RC, Cory JM, Webb KA, O'Donnell DE. Inspiratory capacity during exercise: measurement, analysis, and interpretation. Pulm Med 2013;2013:1-13.

9. Brooks D, Solway S, Gibbons WJ. ATS statement on six-minute walk test. Am J Respir Crit Care Med 2003;167(9):1287.

10. Attinger A, Tuller C, Souren T, Tamm M, Schindler C, Brutsche $\mathrm{MH}$. Feasibility of mobile cardiopulmonary exercise testing. Swiss Med Wkly 2006;136(1-2):13-18.

11. Hannink J, Lahaije A, Verberkt C, Dekhuijzen R, van Helvoort H, Heijdra Y. Validity of Oxycon Mobile in measuring inspiratory capacity in healthy subjects. Clin Physiol Funct Imaging 2010;30(3): 206-209.

12. Satake M, Shioya T, Uemura S, Takahashi H, Sugawara K, Kasai C, et al. Dynamic hyperinflation and dyspnea during the 6-minute walk test in stable chronic obstructive pulmonary disease patients. Int J Chron Obstruct Pulmon Dis 2015;10:153-158.

13. Miller MR, Hankinson J, Brusasco V, Burgos F, Casaburi R, Coates A, et al. Standardisation of spirometry. Eur Respir J 2005;26(2):319338.

14. van Helvoort HA, Heijdra YF, de Boer RC, Swinkels A, Thijs HM, Dekhuijzen PN. Six-minute walking-induced systemic inflammation and oxidative stress in muscle-wasted COPD patients. Chest 2007; 131(2):439-445.

15. Marin JM, Carrizo SJ, Gascon M, Sanchez A, Gallego B, Celli BR. Inspiratory capacity, dynamic hyperinflation, breathlessness, and exercise performance during the 6-minute-walk test in chronic obstructive pulmonary disease. Am J Respir Crit Care Med 2001;163(6): 1395-1399. 


\section{Measuring Dynamic Hyperinflation During 6MWT}

16. Kern L, Condrau S, Baty F, Wiegand J, van Gestel AJ, Azzola A, et al. Oxygen kinetics during 6-minute walk tests in patients with cardiovascular and pulmonary disease. BMC Pulm Med 2014;14:167.

17. Sadaria KS, Bohannon R. The 6-minute walk test: A brief review of the literature. Clin Exerc Physiol 2001;3(3):127-132.

18. Troosters T, Vilaro J, Rabinovich R, Casas A, Barbera JA, Rodriguez-Roisin R, et al. Physiological responses to the 6-min walk test in patients with chronic obstructive pulmonary disease. Eur Respir J 2002;20(3):564-569.

19. Turner SE, Eastwood PR, Cecins NM, Hillman DR, Jenkins SC. Physiologic responses to incremental and self-paced exercise in COPD: a comparison of three tests. Chest 2004;126(3):766-773.

20. Miles DS, Critz JB, Knowlton RG. Cardiovascular, metabolic, and ventilatory responses of women to equivalent cycle ergometer and treadmill exercise. Med Sci Sports Exerc 1980;12(1):14-19.

21. Bennell K, Dobson F, Hinman R. Measures of physical performance assessments: self-paced walk test (SPWT), stair climb test (SCT), six-minute walk test (6MWT), chair stand test (CST), timed up \& go (TUG), sock test, lift and carry test (LCT), and car task. Arthritis Care Res (Hoboken) 2011;63(Suppl 11):S350-S370.

22. Perret C, Mueller G. Validation of a new portable ergospirometric device (Oxycon Mobile) during exercise. Int J Sports Med 2006; 27(5):363-367.

23. Soffler MI, Hayes MM, Schwartzstein RM. Respiratory sensations in dynamic hyperinflation: physiological and clinical applications. Respir Care 2017;62(9):1212-1223.
24. Zafar MA, Tsuang W, Lach L, Eschenbacher W, Panos RJ. Dynamic hyperinflation correlates with exertional oxygen desaturation in patients with chronic obstructive pulmonary disease. Lung 2013;191(2): 177-182.

25. van Noord JA, Aumann JL, Janssens E, Verhaert J, Smeets JJ, Mueller A, et al. Effects of tiotropium with and without formoterol on airflow obstruction and resting hyperinflation in patients with COPD. Chest 2006;129(3):509-517.

26. O’Donnell DE, Fluge T, Gerken F, Hamilton A, Webb K, Aguilaniu $\mathrm{B}$, et al. Effects of tiotropium on lung hyperinflation, dyspnoea and exercise tolerance in COPD. Eur Respir J 2004;23(6):832-840.

27. Tueller C, Kern L, Azzola A, Baty F, Condrau S, Wiegand J, et al. Six-minute walk test enhanced by mobile telemetric cardiopulmonary monitoring. Respiration 2010;80(5):410-418.

28. Sciurba F, Criner GJ, Lee SM, Mohsenifar Z, Shade D, Slivka W, et al. Six-minute walk distance in chronic obstructive pulmonary disease: reproducibility and effect of walking course layout and length. Am J Respir Crit Care Med 2003;167(11):1522-1527.

29. Callens E, Graba S, Gillet-Juvin K, Essalhi M, Bidaud-Chevalier $\mathrm{B}$, Peiffer $\mathrm{C}$, et al. Measurement of dynamic hyperinflation after a 6-minute walk test in patients with COPD. Chest 2009;136(6): 1466-1472.

30. Rossi A, Aisanov Z, Avdeev S, Di Maria G, Donner CF, Izquierdo $\mathrm{JL}$, et al. Mechanisms, assessment and therapeutic implications of lung hyperinflation in COPD. Respir Med 2015;109(7):785-802. 